\title{
Jemparingan Tradition as a Traditional Media to Shaping The Character of Teenagers in Klaten
}

\author{
Derena Martha Yohanda ${ }^{1 *}$, Hafiz Aziz Ahmad ${ }^{2}$ \\ ${ }^{I}$ Institut Teknologi Bandung, Indonesia \\ ${ }^{2}$ Institut Teknologi Bandung, Indonesia \\ *Corresponding author.Email: derenadera@gmail.com
}

\begin{abstract}
The adolescent is an entire instability and self-identity searching period, hence in adolescence, adverse action is susceptible. Character shaping in this period is suitable to be applied by embedding positive and cultural values to become a person with strong character as a provision in the future. One of the ways in shaping a character is by introducing the teenager with jemparingan. Jemparingan is a traditional archery that contains many core values. Jemparingan also has a unique character that is it conducts by sitting cross-legged and wearing traditional clothes or attributes. This research aimed to learn values in jemparingan tradition, comprehend positive values in jemparingan activity, and find jemparingan role in building teenager character. Method used in this research was qualitative data collection done by observation assisted by observation paper as the research reference material, teenager jemparingan activity documentation, and literature research dealing with the research topic. This research was conducted in 2021 at Sasana Jemparingan Pandawa. Sasana Jemparingan Pandawa is one of the places for jemparingan gathering from various regions located at Klaten Regency. This research showed that jemparingan tradition could be used as character shaping such as self-confidence, self-esteem, unyielding stiffness, honesty, mutual respect, responsibility, independence, patriotism, discipline, and hard work. The other significant result in this research was that positive values in jemparingan tradition were a medium for socializing among teenagers and a medium for culture-based community.
\end{abstract}

Keywords: Character, Jemparingan Tradition, Value, Teenager, Traditional

\section{INTRODUCTION}

Adolescence is one of the phases in a person stages lives. It is also one of the essential stages because this is a transition stage from childhood to adulthood. In this stage, Someone who goes around between 10-24 years old is called as a teenager[1]. This stage is wellknown as a complete instability stage in searching for self-identity. Teenagers do not have a clear position, they are no longer included in the children group, but they cannot fully accept as the adult group yet. Therefore, adolescence is generally called as "searching self-identity" phase or "hurricane and storm". Teenagers still not be able to control and use their physical and psychological functions. However, adolescence is a development stage in a very potential period viewing from its cognitive aspect, emotion, or physical [2]. It is suitable with the prior statement and reality that happens in self-identity searching from many teenagers that addicted to negative actions because they still cannot maximize their psychical function and are encouraged by their curiosity. Teenage's negative actions are often called juvenile delinquency. Juvenile delinquency is the action that a teenager does by ignoring social values that are applied in society. Juvenile delinquency consists of all activities that deviate with social and law norms that teenager carries out. This action can harm them and the people around them [3]. The example of juvenile delinquency are engaging in a gang fight, street racing illegally, stealing, cheating, consuming drugs, doing free sex, and so on.

Character shaping in teenagers is essential to make them not fall into negative things and harm other people. Moreover, the teenage character will significantly affect their future. Character is behavior, mental traits, morals, or clarity that distinguishes someone from others and disposition [4]. One of the ways in shaping teenage characters is by introducing 
them to jemparingan tradition. Jemparingan tradition is traditional archery that has many core and positive values. Its unique characteristic is it conducts by sitting cross-legged and waering traditional clothes or attributes. Jemparingan tradition came from Mataram Monarchy and became one of the non-object cultural heritages. Sultan Hamengku Buwono I, as the first king in the Kingdom of Mataram taught rapids to his soldiers as a means of forming a knight character. Therefore, the tradition of jemparingan is a traditional medium that is effectively used to form character in teenagers.

This research aimed to learn values in jemparingan tradition, comprehend positive influences perceived by the teenager jemparingan player after joining jemparingan activity, and find jemparingan role in shaping a character for teenagers.

Headings may be numbered or unnumbered ("1 Introduction" and "1.2 Numbered level 2 head"), with no ending punctuation. As demonstrated in this document, the initial paragraph after a heading is not indented.

\section{METHODOLOGY}

The method used in this research was qualitative with observation type research. By conducting a qualitative with observation type research, the data collection was expected to be accurate and valid to explain occurred phenomenon depiction. This research was conducted in 2021 that located at Sasana Jemparingan Pandawa. Sasana Jemparingan Pandawa was one of the archery fields that became a jemparingan association gathering place from various regions located in Klaten Regency.

Technic used in this research was a direct observation that helped by observation instrument in the form of questionnaire research and jemparingan activity documentation. Observation technic was done by visiting the place several times to observe the practice amongst jemparingan association to obtain actual depiction of jemparingan activity. For comprehending the accepted influence by teenager jemparingan players, a questionnaire fulfillment was applied. Then, documentation was carried out to understand the condition when the observation was going through.

Data processing method, observation data analysis result, questionnaire paper, and documentation were done by descriptive qualitatively for finding out jemparingan role for teenager. The analysis result from the questionnaire served in the form of a table that contained total score, percentage, and category.
The questionnaire paper measurement scale consisted of $\mathrm{A}=$ Always, $\mathrm{R}=$ Rarely, and $\mathrm{N}=$ Never, meanwhile, the category used low, average, and high. The questionnaire paper was distributing and fulfilling when jemparingan activity was done. Seven players fulfilled the questionnaire, and they were KM (19), MR (19), AM (16), RR (17), FA (14), RP (22), and NI (20).

There were ten questions in the questionnaire page dealing with values and positive behaviors that showed in Table 1, as follows:

Table 1. Questionnaire list

\begin{tabular}{|c|l|}
\hline No & \multicolumn{1}{|c|}{ Question } \\
\hline 1 & Does jemparingan train your self-confidence? \\
\hline 2 & $\begin{array}{l}\text { Does jemparingan train you to appreciate other's } \\
\text { achievements? }\end{array}$ \\
\hline 3 & Does jemparingan train you to never give up? \\
\hline 4 & $\begin{array}{l}\text { Does jemparingan train you to respect other's } \\
\text { opinions? }\end{array}$ \\
\hline 5 & $\begin{array}{l}\text { Does jemparingan train you to be an honest } \\
\text { person? }\end{array}$ \\
\hline 6 & Does jemparingan train you to be responsible? \\
\hline 7 & $\begin{array}{l}\text { Does jemparingan train you to become } \\
\text { independent? }\end{array}$ \\
\hline 8 & $\begin{array}{l}\text { Does jemparingan train you to love your } \\
\text { country? }\end{array}$ \\
\hline 9 & $\begin{array}{l}\text { Does jemparingan train you to become a } \\
\text { disciplined person? }\end{array}$ \\
\hline 10 & $\begin{array}{l}\text { Does jemparingan train you to be a hard-working } \\
\text { person? }\end{array}$ \\
\hline
\end{tabular}

\section{JEMPARINGAN TRADITION}

For comprehending that jemparingan tradition could be a traditional method to build teenager character, an observation assisted with questionnaire paper and jemparingan activity documentation in Sasana Jemparingan Pandawa located at Klaten Regency. Observation was conducted by examining jemparingan practice implementation. Jemparingan is a traditional archery that came from Mataram Kingdom. Jemparingan origins from the Javanese language 'Jemparing', which means arrows. It has pamenthanging gandewa pamanthenging cipta philosophy that means spreading out bow accompanied by concentration to one target. This philosophy has a definition that is when undergoing daily life, we have to focus on our live purposes to reach our dreams.

The male or female person can play jemparingan from the child until old age people. There is no limit to jemparingan player numbers. At the time of competition, jemparingan is required to use traditional 
clothing, for men using surjan, batik cloth and blangkon / udeng and for women using kebaya. While at the time of training jemparingan only uses attributes such as udeng / blangkon, this is done because in addition to functioning as a sport, we also need to appreciate and preserve the culture. Jemparingan was carried out with sitting cross-legged in position 90 degrees, this is like the proverb of sitting equally low and standing equally high which means in doing jemparingan whoever has the same position, whether from the government, leaders, officials or ordinary people. The tools used for jemparingan are mostly made of wood and bamboo material such as its bow, wings and arrow. This jemparingan equipment is personal and difficult to lend because each tool will adjust the posture to the size of the bow and the length of the hand for the size of the arrow, this adjustment is highly recommended for convenience and can perform jemparingan activities to the maximum. The treatment of arrows is also not an easy thing, because it takes careful checking the condition of the wood to keep dry so as not to grow mushrooms and be eaten by small insects on the bow and arrow.

The target in jemparingan is called bandolan or wong-wongan, this bandolan is tubular that contains a banana steam wrapped with cloth that is likened to a person, in the connecting wire between the bandolan and the support pole there is a small bell, this bell will ring when there is an arrow stuck to the bandolan. The distance between the shoot bow position with the target is around 30 meters.

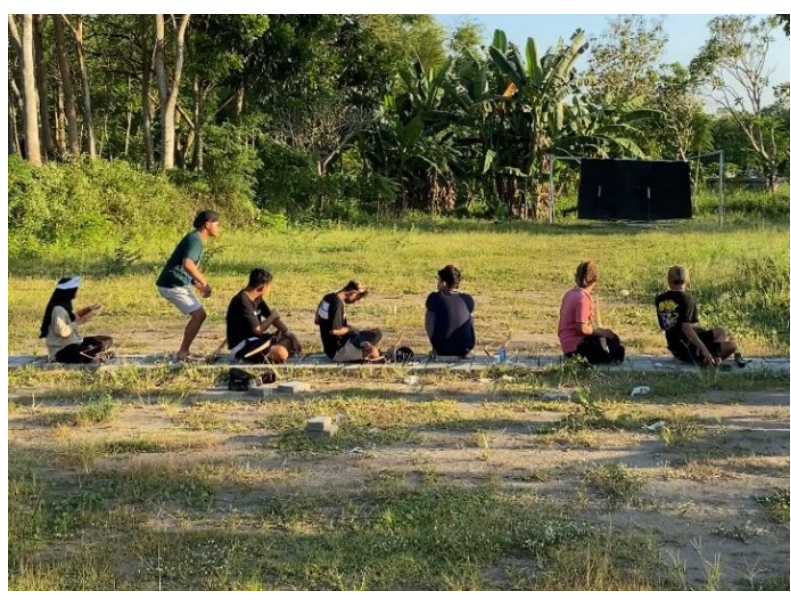

Figure 1 Preparation for jemparingan exercises

The steps in the jemparingan game start with teenager jemparingan players visiting Sasana Jemparingan Pandawa, then prepared tools that would be used, such as setting the bow rope, choosing arrows to use, and wearing casual clothes as well as attributes such as udeng or blangkon for male players and iket for female players. They did hand muscle, head, and back stretching while chatting with each other. After all jemparingan players were ready to sit cross-legged in their position, then they practiced jemparingan together started by following the command from one of the players. Jemparingan used three commands: Siaga, which means get ready; Wiwit, which implies start; and Rampung, which means finish. There were 20 rounds in jemparingan, in which each round, the archer was given a chance to shoot four arrows. Then, he took arrows from the target location before sitting back in his position. Siaga and Wiwit were used when each round was started, while Rampung was used after each round finished.

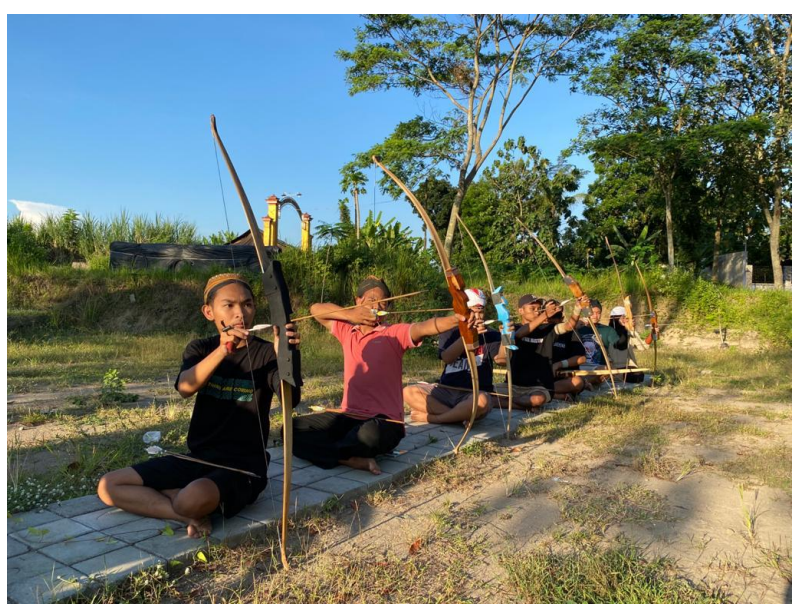

Figure 2 Teenagers practice jemparingan

While the practice was going through, the teenager jemparingan players enjoyed the activity in each round casually and confidently. Once in a while, after shooting four arrows, the players took their time to drink and eat snacks while waiting for the other players done to plug the arrows. They were often teasing each other when they missed shoot from the target. Then, in the round alteration, teenager players took arrows by walking and talking to each other about the lacks in the prior round. Quite draining, these darts take will be equivalent to walking $1.2 \mathrm{~km}$ if totaled 20 rounds in one exercise, but this distance does not end the spirit of the youth to practice jemparingan.

After they arrived at the target location, the players that could shoot the target would count and summed up the scores independently until the game was ended. There were two parts in the target that were top and bottom, the top part was red-colored that represented as head, and the bottom part was white-colored that defined body, if the arrows shot on the head so the player would gain three scores, meanwhile if the player shot the body they would achieve one score. 


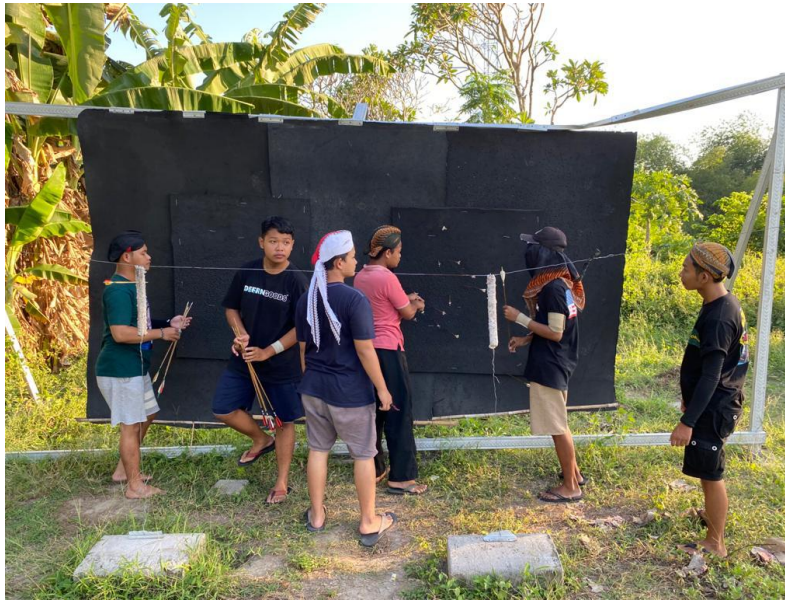

Figure 3 Arrow retrieval

After the players took the arrows and back to their position, they evaluated their errors in the prior round. Sometimes, the credible player would help and give the new players suggestions to make their archery technic better and could right on the target. After all activities in jemparingan finished, the teenage players described the values they got during the game. The youth accept and appreciate each other's worth by congratulating each other in jemparingan, the name for the winner is "titis", titis comes from javanese language that has the meaning of right on target.

Following the finished game, the teenagers did not go directly from the field but gathered to discuss the playing technic, errors, and obstacles during the jemparingan game. Before they ended their discussion, the teenagers planned the following practice time. Finally, they left Sasana Jemparingan Pandawa together.

\section{DATA, ANALYSIS AND DISCUSSION}

The result of questionnaire paper with ten questions was showed in Table 2 as follows:

Table 2. Questionnaire result

\begin{tabular}{|c|c|c|c|}
\hline Name & Always & Rarely & Never \\
\hline KM & 7 & 3 & 0 \\
\hline MR & 9 & 1 & 0 \\
\hline AM & 7 & 3 & 0 \\
\hline RR & 6 & 4 & 0 \\
\hline FA & 5 & 5 & 0 \\
\hline RP & 8 & 2 & 0 \\
\hline NI & 8 & 2 & 0 \\
\hline
\end{tabular}

From the results above, then the data were processed by giving scores as follows: Always $=10$,
Rarely $=5$, and Never $=1$. The next step was counting the percentage and categorizing the score with measurement: low $7-38 \%$, average $39-70 \%$, and high $71-100 \%$. The value is calculated using the linkert scale.

Table 3. Questionnaire data processing result

\begin{tabular}{|c|c|c|c|}
\hline Name & Total Score & Percentage & Category \\
\hline KM & 85 & $85 \%$ & High \\
\hline MR & 95 & $95 \%$ & High \\
\hline AM & 85 & $85 \%$ & High \\
\hline RR & 80 & $80 \%$ & High \\
\hline FA & 80 & $80 \%$ & High \\
\hline RP & 90 & $90 \%$ & High \\
\hline NI & 90 & $90 \%$ & High \\
\hline
\end{tabular}

The data processing indicated that all respondents could be classified in the high category, which means self-confidence, self-esteem, unyielding stiffness, honesty, mutual respect, responsibility, independence, patriotism, discipline, and hard work. Jemparingan actualization values were presented in Table 4

Table 4. Questionnaire data processing result

\begin{tabular}{|c|c|}
\hline $\begin{array}{l}\text { Character } \\
\text { values }\end{array}$ & Description \\
\hline $\begin{array}{c}\text { Self- } \\
\text { confidence }\end{array}$ & $\begin{array}{l}\text { Joining jemparingan activity } \\
\text { confidently, playing jemparingan game } \\
\text { confidently, becoming confident with } \\
\text { the obtained result. }\end{array}$ \\
\hline Self-esteem & $\begin{array}{l}\text { Admitting and respecting achievement } \\
\text { or score amongst jemparingan player, } \\
\text { giving appreciation for other players. }\end{array}$ \\
\hline $\begin{array}{c}\text { Unyielding } \\
\text { stiffness }\end{array}$ & $\begin{array}{l}\text { Having high enthusiasm towards } \\
\text { jemparingan, follwing jemparingan } \\
\text { practice passionately from the } \\
\text { beginning until the game's final. }\end{array}$ \\
\hline $\begin{array}{l}\text { Mutual } \\
\text { respect }\end{array}$ & $\begin{array}{l}\text { Having tolerance from others players } \\
\text { opinion }\end{array}$ \\
\hline Honesty & Declaring the obtained result honestly. \\
\hline Responsible & Joining the practice seriously. \\
\hline $\begin{array}{c}\text { Independenc } \\
\mathrm{e}\end{array}$ & $\begin{array}{l}\text { Not relying on or interfering with other } \\
\text { players like in taking the stroked } \\
\text { archeries. }\end{array}$ \\
\hline Patriotism & $\begin{array}{l}\text { Admitting and participate in preserving } \\
\text { the tradition of jemparingan as } \\
\text { Indonesian culture. }\end{array}$ \\
\hline Discipline & Not obstructing jemparing games. \\
\hline Hardwork & $\begin{array}{l}\text { Playing jemparingan seriously to gain } \\
\text { high result. }\end{array}$ \\
\hline
\end{tabular}


According to the description above, jemparingan tradition contained benefits such as sport, aesthetics, and entertainment. The other benefit was the jemparingan players could learn positive and cultural values in jemparingan tradition. Those values involved self-confidence, self-esteem, unyielding stiffness, honesty, mutual respect, responsibility, independence, patriotism, discipline, and hard work. For teenagers, those values would help to shape their character. In addition, the jemparingan tradition could become a media for socializing between teenagers and sharing knowledge concerning this noble tradition.

\section{CONCLUSION}

From the complete analysis results, it can be concluded that in this time of self-discovery, it is undeniably very vulnerable to deviant deeds because their psychic growth is not perfect, and the spirit of adventure and curiosity about new things are very high. Therefore, adolescence must be equipped with a strong character in accordance with positive values and adiluhung.

The values in jemparingan tradition can be used as character shaping such as self-confidence, selfesteem, unyielding stiffness, honesty, mutual respect, responsibility, independence, patriotism, discipline, and hard work. The process contained in each jemparingan activity ranging from sitting, archery, taking arrows to return to sit has its values and meanings, the values are interrelated and can be a picture of social life that occurs everyday. Moreover, jemparingan activity has positive values for teenagers as a socialization media and culture-based community. Therefore, it can build their strong character and prevent them from doing negative actions such as juvenile delinquency.

This research has considered using the method because measuring character formation will take a long time. To get a depiction of a character formation is not enough with several visits, it takes observation and retrieval of advanced data for a long period. Therefore, the position of this research becomes preliminary research or preliminary data as the basis for further research.

\section{AUTHORS' CONTRIBUTIONS}

DMY carried out the literature survey and poll, analysed the data and wrote the manuscript. HAA as a guidance and assistance.

\section{ACKNOWLEDGMENTS}

Thanks to the members of the PJKM and Ronggo Sedayu communities for contributing to this research. Also Bandung Institute of Technology has supported and assisted this research until completion. And all parties who support finance this paper until it was completed and published.

\section{REFERENCES}

[1] Mengenal Remaja Generasi Z (Dalam Rangka Memperingati Hari Remaja Internasional) [Internet]. 2019 [cited 2021 July 21]. Available from: http://ntb.bkkbn.go.id/?p=1467

[2] Remaja adalah. 2021 [cited 2021 Juny 15]. DOI: https://www.dosenpendidikan.co.id/remajaadalah/

[3] Kenakalan Remaja (Juvenile Delinquency) [Intenet]. 2019 [cited 2021 Juny 15]. DOI: https://www.kajianpustaka.com/2019/08/kenaka lan-remaja-juvenile-delinquency.html

[4] KBBI Daring. 2016 [cited 2021 Juny 17]. DOI: https://kbbi.kemdikbud.go.id/entri/karakter

[5] Jemparingan Gaya Mataraman [Internet]. 2018 [cited 2021 Juny 16]. DOI: https://www.kratonjogja.id/takbenda/lainnya/14/jemparingan-gaya-mataram

[6] Fauzi. Pembentukan Karakter Anak Melalui Permainan Tradisional Cim-ciman. Jurnal Ilmiah VISI PPTK PAUDNI. 2016;11(2):99-109

[7] Jemparingan, Seni Panahan Asli Yogyakarta Yang Sarat [Internet]. 2019 [cited 2021 July 20]. DOI:

https://indonesia.go.id/kategori/keanekaragaman -hayati/931/jemparingan-seni-panahan-asliyogyakarta-yang-sarat-arti. 